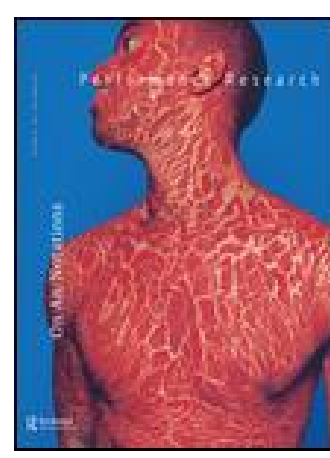

Performance Research

A Journal of the Performing Arts

ISSN: 1352-8165 (Print) 1469-9990 (Online) Journal homepage: http://www.tandfonline.com/loi/rprs20

\title{
Worlds of MoCap
}

\section{Laura Karreman}

To cite this article: Laura Karreman (2015) Worlds of MoCap, Performance Research, 20:6, 35-42, DOI: $10.1080 / 13528165.2015 .1111049$

To link to this article: http://dx.doi.org/10.1080/13528165.2015.1111049

\section{曲 Published online: 26 Nov 2015.}

Submit your article to this journal $\pi$

Lll Article views: 11

Q View related articles $\longleftarrow$

View Crossmark data ¿ 


\title{
Worlds of MoCap \\ Writing dance on a three-dimensional canvas
}

\author{
LA URA KARREMAN
}

Exercise: Imagine a writing instrument located at the top of your head, at the soft spot where the bones of the skull meet. Imagine you can draw with this instrument as a sky-writing plane draws in space. The space around you is a three dimensional canvas.

John Gamble (1977: n.p.)

'If there really were a writing instrument on the top of the head', Ann Cooper Albright remarks on this dance improvisation exercise, 'it would probably draw something like a hieroglyph' (1989:42). Cooper Albright refers to the handwritten hieroglyphs by Nancy Stark Smith that were inspired by her practice of contact improvisation. ${ }^{1}$

Because of the ability of motion capture (MoCap) technology to record the threedimensional contour of the body of the performer, motion data of a dancer's body have now become a prominent source for digital representations of dance. Drawing a line with the top of your head on a three-dimensional canvas is no longer a mere exercise of the imagination. In fact, Motion Bank's digital score Using the Sky (2013) based on Deborah Hay's choreography No Time To Fly does just that: 'Travel paths' that trace the movement of dancers were digitally drawn through markerless movement capture, enabling the viewer to distinguish individual differences between the dancer's movement patterns.

In this article I examine the contemporary phenomenon of MoCap-based renderings of dance. Taking Nancy Stark Smith's hieroglyphs and Motion Bank's digital score Using the Sky as my main examples, I draw a comparison between analogue and digital traces of dance that both rely on principles of capture instead of following a symbolic notation system. Although one is created by an ink pen and the other by a MoCap apparatus, these different types of drawing display some striking similarities. At the same time there are some fundamental differences in the ontological basis of these images, which affects the way in which we relate to these images and how they invite us to understand dance. Whereas the role of the dancing body as 'drawing instrument' remains present, this metaphor manifests itself in a different way in its digital surroundings. What do these digital traces of dance depict? And who is doing the drawing?

\section{PHENOMENAL DANCE IMAGES}

Writing with a black ink pen, Nancy Stark Smith started to make quick and expressive drawings as a reflection on her own dancing or while watching others dance (fig. 1). Stark Smith was interested in 'what happens between an experience and the telling of it, the translation from one medium to another' (1982:45). The hieroglyphs were open to interpretation and

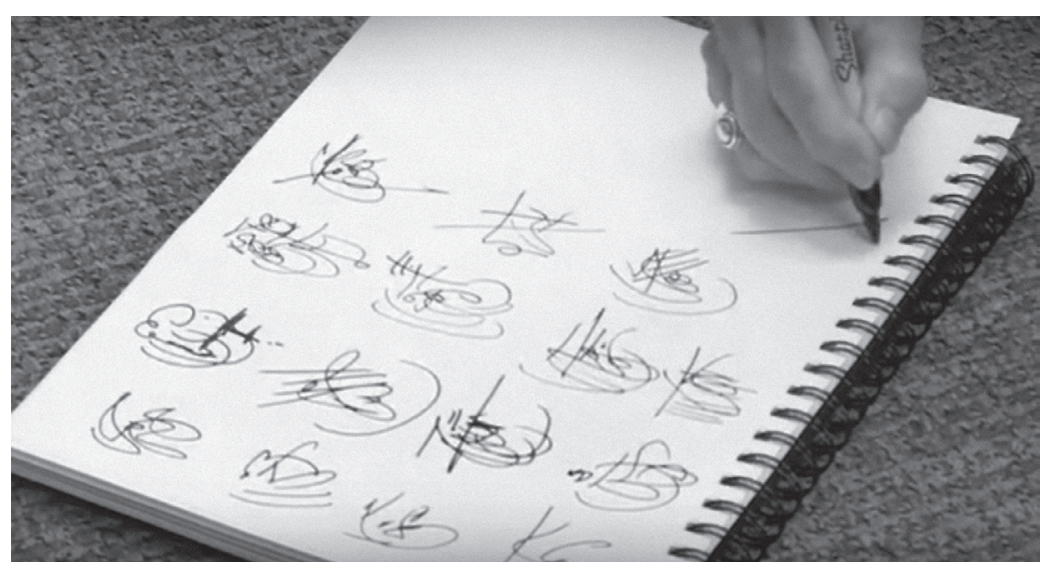

${ }^{1}$ Contact improvisation is an improvisational dance practice developed in the 1970s by Steve Paxton in collaboration with Nancy Stark Smith and others that built on the experimental ideas of the Judson Dance Theater (an informal group of dancers who performed in Manhattan, New York City in the early 1960s) and the principles of Aikido.

Figure 1. Nancy Stark Smith writing hieroglyphs. Video by Meta-academy@ Bates 2013: Minded Motion Lab (Marlon Barrios Solano et al 2013). Video editor and camera: Rachel Boggia. camera: Rachel Boggia. 
never aimed to describe a concrete movement phrase: 'A squiggly line could as well be a pathway on the floor as an S curving through the body' (Cooper Albright 1989:42). In her attempt to avoid a fixation of dance as it occurs in symbolic movement notation, Stark Smith found that this type of dance writing managed to both embody the subjectivity of the writer and to convey the fluidity of dance as creative practice.

Continuing a dance writing practice she has taught for more than three decades, Nancy Stark Smith, still a prominent figure in the field of contact improvisation, continues to teach the drawing of hieroglyphs as part of her workshops. An excerpt of a recent online video tutorial shows that her instruction of this practice has virtually remained unchanged since the beginning of the 1980s:

You allow a bit of body energy to move on the page in an area. They're individual units of movement, you could say. I call these 'glyphs': an extension of the energy of your body that comes out in the space. It's almost a little conversation with yourself as you go from glyph to glyph. It's not so much thinking about it as it is reconnecting to the body and extending out into the page and moving.... [After you have finished a page] put your pen down and look at what you wrote. You might have your favourite or there might be something about the movement that feels balanced or unbalanced, amusing or confusing. (Barrios Solano et al. 2013)

The online availability of the tutorial enables participants to share their thoughts on the process and pictures of their own glyphs (Barrios Solano et al. 2013). One participant comments: 'Fascinating ... my sense of orientation to the paper vis-a-vis my inner body - amazing in what is felt vs what is drawn - I'm calling the drawing my 'TKG' - tensile kinetic graphic' (Batson 2013). Rather than functioning as a score or document, then, the glyphs fulfil the aim of reflecting on dance improvisation sessions without describing too much. Stark Smith observes: 'An inspiring dance can be quickly flattened when the mind closes in around it trying too quickly to define and enclose the experience. The point, it seems, is to bring something forward, not to close it in' (Stark Smith 1982:45). The hieroglyphs are part of what Stark Smith calls 'harvest', a reflection of the performer after an improvisation session. The glyph writing offers the performer an opportunity to reflect on what happened during the session, which seems to function as a valuable tool to sharpen the proprioceptive abilities of the dancer.

Stark Smith's drawing of hieroglyphs reminds of somebody writing their signature. They flow out of her pen in a way that seems simultaneously impulsive and deliberate. As opposed to a signature, however, these movement signatures are all unique, although they tend to share a recognizable 'style' - Stark Smith, who calls them 'self-styled symbols', has noticed the similarity with her handwriting (Stark Smith 1982:45). These 'unique insignias of a moving body', as Cooper Albright called them, are quite different symbols than Egyptian hieroglyphics, as they are not part of an established symbolic writing system (Cooper Albright 1989:36). The choice to use the term 'hieroglyphs' can be explained from a different angle. As opposed to alphabetic language, Egyptian hieroglyphics display a visual connection to what they represent, as do Chinese characters and Mayan glyphs (Rotman 2008:124). The dance glyphs also connect to the dance, through a connection that is both visual and experiential. By transposing the dance to written marks, the glyphs produce a kinaesthetic expression of the dance that enables the dancer to reflect on their experience.

Moreover, this reflection is not merely of an intellectual nature, but involves an embodied response. This observation is further clarified by Nigel Stewart (1998), who argues that Stark Smith's hieroglyphs can be understood as 'phenomenal dance images' (49). Stewart defines phenomenal dance images as expressive figures that convey the 'forcetimespace' of dance, a term Sheets-Johnstone has used to describe the 'indivisible wholeness' of dance (1979: 14). The effect of the hieroglyphs indeed goes beyond a visual depiction of the movement. As Stewart observes: 
${ }^{2}$ The specific approach of the markerless motion capture for Motion Bank was developed by Fraunhofer IGD and TU Darmstadt (Kahn et al. 2012).

${ }^{3}$ 'Capturing Stillness: Visualisations of dance through motion capture technologies' (2010-13) by Ruth Gibson is a relevant example of an artistic research project that challenged this spatial bias by aiming to map dance movements emerging from the somatic practice of Skinner Releasing Technique. One of the key questions of this project was 'whether stillness remains invisible when no motion can be tracked or whether stillness becomes replete with life as the visualisation process gives life to the dancing avatar' (Whatley 2011:274). systems, capturing technologies like MoCap offer the advantage of a continuous topological model, which allows for an easier retainment of the affective quality of the movement. The difference between capture and notation here is of crucial importance. Instead of translating movement into symbols, as is done when speech is transposed into writing, gesturo-haptic writing is a 'mediating technology that escapes purely signifying and the representational by operating within interactive, participatory, and immersive regimes' (Rotman 2002:435). The only way for us to 'read' MoCap's written traces, then, seems to be to perform or 're-enact' the gesture on display.

Although the metaphor of the dancing body as instrument of writing is present in both Motion Bank's travel paths and Stark Smith's hieroglyphs, a comparison of these images also shows fundamental differences. These differences revolve around what the written trace depicts and who is involved in the writing.

Let us first of all look at what the digital trace depicts in Using the Sky (fig. 2). The travel paths in Using the Sky are based on the movement trajectory of the (approximate) centre of the body of three different performers of Deborah Hay's score No Time To Fly, who have been captured through markerless motion capture, enabled by the use of Kinect sensor cameras. ${ }^{2}$ The digital score's interface allows for a simultaneous view of multimodal sources. The score is structured in accordance with a division of Deborah Hay's score in twenty-five parts. For each part, we can view the travel path images, Hay's written score and the dancer's account of their insights on performing the score. A video capture of the performance is also available. For example, when Hay's score in section twelve reads 'I move across the stage in a straight line while erasing my destination', next to it we read performer Jeanine Durning's commentary:

I always am aware of this diagonal but I'm trying to erase it at the same time, I don't want to give away that I'm travelling in this direction, so in this way I'm also constantly in negotiation with the audience and trying to maybe understand how they're perceiving this pathway and trying to trick them to not see it any more.

(Motion Bank 2013)
The blue travel path that corresponds with Durning's movement clearly follows a diagonal across the stage, but instead of a 'straight line' it shows an erratic sequence of tiny detours and divergences. The messy diagonal we perceive in the travel path starts to make sense when making the connection to the attempt to 'trick the audience', Durning's interpretation of the instruction in Hay's score to 'erase her destination'. Rather than just a messily drawn diagonal, we may now be able to recognize other features in the image that are related to the interpretation of the score, such as hesitance, negotiation and playfulness. The juxtaposition of these different sources has the effect that the travel path image becomes more than a display of a movement trajectory, but also acquires the expressive force that Stewart associates with the 'phenomenal dance image'. Furthermore, in accordance with the logic of gesturo-haptic writing that Rotman proposes, the image invites us to 'step inside', to imagine the experiential perspective of the performer.

Even though we can consider both travel path and hieroglyphs as phenomenal dance images, the linear traces they consist of are the result of a different process. Cooper Albright may comment that a writing instrument on the top of the head 'would probably draw something like a hieroglyph', but we can understand from Stark Smith's description of the practice and by looking at examples of glyphs that the spatial description of dance is but one of the aspects reflected in the drawing. Even more than about the outward appearance of the dance, the glyphs capture the internal, proprioceptive experience of the dancer. By only capturing the spatial trajectory of the body's contour in space, the MoCap apparatus radically abstracts dance movements. Its inability to capture anything but the movement of bodies from a to $b$ results in what I would call the 'spatial bias' of MoCapbased dance renderings: a tendency to give preference to dance with a 'large movement amplitude', be it in the body itself - think of the extension of legs and arms - or distributed in trajectories across the stage. ${ }^{3}$ 
FLICKERING SIGNIFIERS

I now turn to the question of who is involved in the writing of MoCap-based dance traces. Whereas the hieroglyphic marks are the result of an intimate interaction between dancer, pen and paper, in the creation of digital dance renderings there are many more agents at play. I will demonstrate this by a closer description of the meaning-making agents in the MoCap apparatus.

In the case of optical motion capture, there are, first, the dancer and the tight-fitting MoCap suit, to which a number of reflective markers are connected. The space in which the dancer is able to move is limited to the capturing volume of the MoCap setting. The invisible beams of infrared cameras, which are set up in a surrounding grid, demarcate the volume that is within reach of the apparatus. Not only the floor surface is limited, also some movements may be out of bounds due to a phenomenon called 'marker occlusion'. Marker occlusion occurs when the infrared cameras lose their stable connection with one of the optical markers on the suit, which makes movements such as intense bending and rolling over the floor difficult to capture. Such movements would result in a lot of 'data gaps', which may be difficult if not impossible to 'repair' in data processing.

To discover the limits of the capturing volume, both on the floor surface and in her movement vocabulary, the dancer may use a projection of a simple rendering of the motion data as visual feedback. As long as the dancer remains within the capturing volume the animation remains smooth and retains a mirror-like continuity. However, as the edge of the capturing frame is reached, the camera's deteriorating data stream can no longer keep the body together. In a desperate-looking attempt to solve the puzzle with too little information, the image starts to shift frantically. Mis-matching limbs start to blink red, which evokes associations with the dashboard interface showing the malfunction of an aircraft engine. Fantastical body anomalies are created in the projected animation when dancing on the edge of the reach of the apparatus. An elbow suddenly connects to a shoulder, a hand sticks out of a hip, an upper thigh suddenly aligns with the spine. The only way to redirect the upset data stream requires the dancer to step 'back inside'. At the centre of the capturing volume she takes on the 'T-pose'. In this position, in which the dancer stands straight up with the arms stretching outwards to the sides at the same level of the shoulders, the body can be recognized again by the system and be re-mapped on the virtual skeleton.

This description makes clear that in addition to the dancer, the suit, the markers, the infrared cameras and the wires that feed the data streams back to the computer, there are even more agents that leave their mark on this process. These are the system operator, the data processor and the designer of the code or software, designed to visually access the data. Furthermore, the design of the frame in which the data are eventually displayed can also be considered as a crucial 'agent' of meaning.

This description also illustrates that the authorial status of a dancer in a MoCap-based creative process is not evident. Even when she is the only dancer on stage, a dancer in a MoCap environment always performs an ensemble rather than a solo. This can be illustrated by an account by performer and dance scholar Steph Hutchison that vividly describes her experience in such a setting:

In a motion capture context, my 'dance partners' are not usually other dancers or even other practices, as is the case in my work outside the motion capture studio. My dance partners in motion capture are markers, animations, motion graphics, avatars and the spatial reality of the motion capture volume.... As anybody who has ever danced a contact improvisation duet with a partner knows, reciprocality and sensitivity is needed rather than force and the assertion of a predefined intention.

(Hutchison and Vincs 2013:1-4)

Hutchison's comparison with contact improvisation invites us to understand her sense of continuously being 'in touch' with the environment as an intimate feedback process between multiple 'bodies' - her own and those 
${ }^{4}$ For example, we can now closely analyse the variability in the execution of a dance phrase (Vincs and Barbour 2013), as well as other features of dance performance that have hardly been studied yet, such as micro movements, repetitive patterns, timing, speed and acceleration. of the other agents involved. The confusion this ambiguous interplay may cause is aptly demonstrated by a contemporary phenomenon in the film industry: despite of outstanding acting performances, for example by Andy Serkis, no actors in motion capture features have up to now been nominated for an Academy Award in the category of Best Actor and neither have digital MoCap artists been nominated for Best Animation (Delbridge 2015:2). Although the co-creational process of actor and technology was already inherent in pre-motion capture cinema, this hybrid format is apparently still too new to acquire the recognition it deserves.

At the same time, this confusion is also understandable. Who are we supposed to give the main credit when the creation process of MoCap-based traces is so profoundly cocreational? The film example illustrates that by abstracting motion data from the performer, the performer themselves runs the risk of disappearing from our radar. For the digital artist, or coder, the motion data is a necessary input, but once they have acquired this data, they are free to adapt and manipulate this data, submit it to algorithms and transpose it to different modes or on to other bodies, which may be inanimate, robotic or even human.

MoCap-based dance traces may well be understood as 'flickering signifiers'. Hayles (1993) introduced this term to describe the unstable relationship between signifier and signified in the binary realm, a relationship that can be changed with a 'single global command'. Hayles explains:

In informatics the signifier can no longer be understood as a single marker, for example an ink mark on a page. Rather it exists as a flexible chain of markers bound together by the arbitrary relations specified by the relevant codes.... As writing yields to flickering signifiers underwritten by binary digits, the narrator becomes not so much a scribe as a cyborg authorized to access the relevant codes.

(Hayles 1993: 77, 87)

The shift from 'scribe to cyborg' that Hayles distinguishes can be recognized in emerging modes of digital dance writing. Depending on their ability to 'access the relevant codes', in co-creative projects such as Motion Bank and, more recently, the Choreographic Coding Labs (2013), the dancer and coder become cyborgs as well as co-narrators in their hybrid creation of flickering signs.

\section{RIGHTNESS OF RENDERING}

I propose to add one last perspective to my discussion of the main questions of this article - What do these digital traces of dance depict? And who is doing the drawing? - a perspective that relates to the 'rightness' of these traces.

Motion capture now offers us what key players in the Western history of dance notation may have considered to be an ultimate opportunity: the visualization of movement in a threedimensionally navigable space and - even more radically - the possibility to map the movement of one body on to other bodies. Each of these renderings highlights different aspects of dance and allows us to ask questions about dance that we have not asked before. ${ }^{4}$ If anything, however, the manipulation of dance motion data confronts us on an even deeper level with the impossibility of creating signs that match the phenomenal nature of dance. As Laurence Louppe wondered in response to early computer-generated choreography by Cunningham in the 1980s in her book Traces of Dance (1994):

Are we not, perhaps like dance masters of the fifteenth century, still far from inventing true signs, finding ourselves stuck in the old pursuit of corporeal truth, where signs, regardless of their nature, merely serve as intermediate means to render this truth in a new form?

(Louppe 1994: 143)

The event of dance capture can be regarded as adding yet another aesthetic form to the 'pursuit of corporeal truth' that Louppe places at the core of the history of dance notation. Could we conceive of contemporary mocapbased visualizations, such as the colourful travel paths in Using the Sky, as 'true signs'?

Instead of mourning the unattainability of 'true signs' of dance, I suggest it is more helpful 
to continue to ask whether a MoCap-based image is rightly designed. I derive the distinction between truth and rightness from Nelson Goodman's seminal book Ways of Worldmaking (1978) in which he proposes that both scientific theories and works of art continuously create worlds that each have their own specific ways of knowing and understanding. In the section 'On Rightness of Rendering', Goodman argues that in our evaluation of renderings of a world 'the distinction between true and false falls far short of marking the general distinction between right and wrong versions' (1978:109). The rightness of design, Goodman emphasizes, is always relative to a system:

Whether a picture is rightly designed or a statement correctly describes is tested by examination and reexamination of the picture or statement and what it refers to in one way or another, by trying its fit in varied applications and with other patterns and statements.

(Goodman 1978:39)

It is this iterative process that can be recognized at the basis of current research projects that experiment with mocap-based renderings. They are aimed at 'testing the picture' and 'trying its fit' in a world of their focus. Now that these researchers - artists, scholars, coders - have gained hands-on experience with this apparatus as a means, it can be seen as a sign of MoCap's growing establishment that it is increasingly taken as a topic or point of reference of new creations. Two examples that illustrate this observation: Steph Hutchison has created meta (2014), a choreography that is based on the typical movement vocabulary she developed while performing in a MoCap setting (Hutchison 2014). Digital artist Amin Weber, who was involved in the creation of Using the Sky, created a computer-generated animation that is his own 'performance' of Deborah Hay's score No Time to Fly (Weber 2013). Although the imagery in this short film is not based on motion data, the design seems nevertheless indebted to the aesthetics of MoCap renderings.

MoCap renderings of dance confront us with our heritage of the history of dance notation. The aesthetics of the linear traces of dance we can now navigate in two-dimensional planes and three-dimensional space still remind of the dance notation that Feuillet created in the seventeenth century, which displayed floor pathways of dancers in combination with a music bar at the top of the page (fig. 3). When these first notational practices planted one of the first seeds, it was in response to the motion capture experiments at the end of the nineteenth century by pioneers such as Eadweard Muybridge and Étienne-Jules Marey that the belief started to gain ground that empirically based movement capture would hold the key to an ultimate truth about the nature of human movement.

While there is no such truth to be found, as Goodman convincingly demonstrates in Ways of Worldmaking, a closer look at contemporary dance capturing practices still reveals glimpses of this idea as a supporting belief. And indeed, even if many features of dance get lost in translation, MoCap does offer us opportunities to create new worlds through which we may start to know dance differently - artistically, by creating new phenomenal images of dance; analytically, by gaining insight in spatial and rhythmical patterns; and gesturo-haptically, by offering the radical opportunity to re-enact the movement through mapping it on to other bodies.

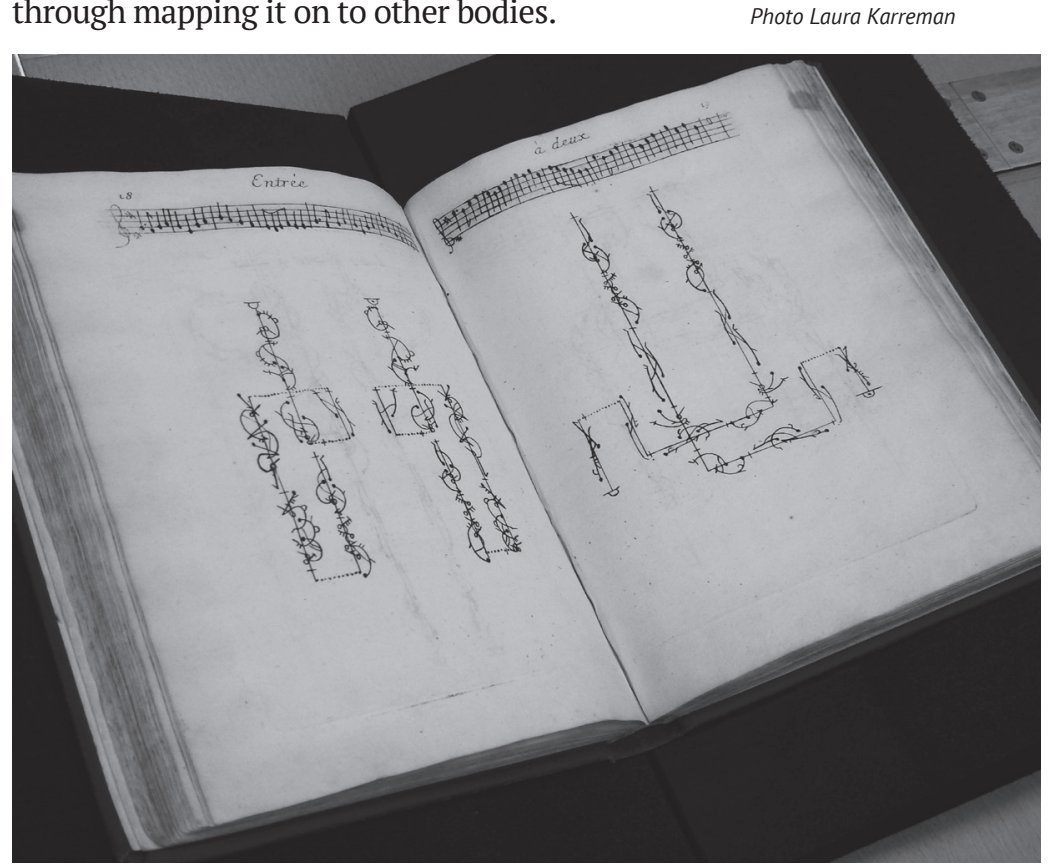

Figure 3. Raoul Auger Feuillet's Chorégraphie, ou l'art de d'écrire la danse (Paris, 1700) on exceptional display in the New York Public Library.

Photo Laura Karreman 
Inherently multi-layered, multi-modal and multi-authored, MoCap-based renderings of dance constitute a complex, but highly interesting cultural phenomenon at a time when motion recognition and haptic technology increasingly affect our society at large. As this practice is located at a crossroads of so many divergent worlds, worlds that are created and supported by the arts, sciences and technologies, it is no wonder that consensus on the 'rightness' of these renderings shifts and will continue to shift - in accordance with the different beliefs and points of view that these worlds afford. Tantalizingly close, but always just out of reach, digital traces of dance shapeshift upon closer approach. Inevitably, as we set our eyes on these flickering motion traces, we continue to grapple with how they present the absence of the dancing body.

The research for this article was made possible by the support of Research Foundation Flanders (FWO).

\section{REFERENCES}

Albright, Ann Cooper (1989) 'Writing the moving body: Nancy Stark Smith and the hieroglyphs', Frontiers: A journal of women studies 10(3): 36-51.

Barrios Solano, Marlon, Nancy Stark Smith, Rachel Boggia and Josephine Dorado (2013) 'CORE: Embodied investigation with Nancy Stark Smith. Hieroglyphs: Embodied activity \#1', Meta-academy at Bates 2013, www. dance-tech.net/group/meta-academy-bates-2013/forum/ topics/core-embodied-investigation-with-nancy-starksmith-week-1, 21 July, accessed 1 July 2015.

Batson, Glenna (2013) 'CORE: Embodied investigation with Nancy Stark Smith. Hieroglyphs: Embodied activity \#1', Meta-academy at Bates 2013, response on 25 July at 3:21 pm, www.dance-tech.net/group/meta-academybates-2013/forum/topics/core-embodied-investigationwith-nancy-stark-smith-week-1, accessed 1 July 2015.

Choreographic Coding Labs (2013), http:// choreographiccoding.org, accessed 1 July 2015.

Delbridge, Matthew (2015) Motion Capture in Performance: An introduction, Houndmills, Basingstoke: Palgrave Macmillan.

Gamble, John (1977) 'On contact improvisation', The Painted Bride Quarterly 4(1): n.p.

Gibson, Ruth (2013) ‘Capturing stillness', www. gibsonmartelli.com/CapturingStillness1.html, accessed 1 July 2015.

Goodman, Nelson (1978) Ways of Worldmaking, Indianapolis, IN: Hackett Publishing.
Hayles, N. Katherine (1993) 'Virtual bodies and flickering signifiers', October 66: 69-91.

Hutchison, Stephanie (2014) meta, www.stephhutchison. com/\#!meta/c6j0, accessed 1 July 2015.

Hutchison, Stephanie and Kim Vincs (2013) 'Dancing in suits: A performer's perspective on the collaborative exchange between self, body, motion capture, animation and audience', in Kathy Cleland, Laura Fisher and Ross Harley (eds) Proceedings of the 19th International Symposium of Electronic Art, ISEA2013, http://ses.library. usyd.edu.au/handle/2123/9475, accessed 1 July 2015.

Kahn, Svenja et al. (2012) ‘Towards an affordable markerless acquisition of intangible contemporary dance choreographies at large-scaled stages', in David Arnold, Jaime Kaminski, Franco Niccolucci and André Stork (eds) The 13th International Symposium on Virtual Reality, Archaeology and Cultural Heritage (VAST), www.igd. fraunhofer.de/sites/default/files/biblio/2012/2012-Kahn markerless-acquisition-contemporary-dance.pdf, accessed 1 July 2015.

Kaiser, Paul (2003) ‘Motion mapping’, in Mike Silver and Diana Balmori (eds) Mapping in the Age of Digital Media: The Yale symposium, Wiley-Academy. http:// openendedgroup.com/writings/motionMapping.html, accessed 1 July 2015.

Louppe, Laurence (1994) 'Notations and drawings', in Laurence Louppe (ed.) Traces of Dance: Drawings and notations of choreographers, Paris: Editions Dis Voir, pp. 133-47.

Motion Bank (2013) Using the Sky, http://scores. motionbank.org/dh, accessed 1 July 2015.

Rotman, Brian (2002) 'Corporeal or gesturo-haptic writing', Configurations 10(3): 423-38.

Rotman, Brian (2008) Becoming Beside Ourselves: The alphabet, ghosts, and distributed human being, Durham, NC: Duke University Press.

Sheets-Johnstone, Maxine (1979) The Phenomenology of Dance, 2nd edn, London: Dance Books.

Smith, Nancy Stark (1982) 'Dance in translation: The hieroglyphs', Contact Quarterly 7(2): 43-6.

Stewart, Nigel (1998) 'Re-languaging the body: Phenomenological description and the dance image', Performance Research 3(2): 42-53.

Vincs, Kim, and Kim Barbour (2013) 'Snapshots of complexity: Using motion capture and principal component analysis to reconceptualise dance', Digital Creativity 25(1): 62-78.

Weber, Amin (2013) 'No time to fly', digital adaptation in Motion Bank, Using the Sky, http://scores.motionbank.org/ $\mathrm{dh} / \# /$ set/digital-adaptation-of no-time-to-fly, accessed 1 July 2015.

Whatley, Sarah (2011) 'The poetics of motion capture and visualisation techniques: The differences between watching real and virtual dancing bodies', in Dee Reynolds and Matthew Reason (eds) Kinesthetic Empathy in Creative and Cultural Practices, Bristol: Intellect, pp. 265-97. 